\title{
EFEKTIFITAS MEDIA QUIZ DI MASA PANDEMI COVID-19
}

\author{
${ }^{1}$ Tarisa Arianda, ${ }^{2}$ Diniatul Mas'ula, ${ }^{3}$ Iga Femelia, ${ }^{4}$ Mohammad Mukhlis \\ 1,2,3,4 UIN Kiai Haji Achmad Siddiq Jember, J1 Mataram No.1 Mangli Kaliwates Jember (68136), 0331-487550 \\ e-mail: tarisaarianda5@gmail.com
}

\begin{abstract}
Abstrak
Tujuan penelitian ini adalah mengetahui efektifitas media Quiziz dalam pembelajaran matematika khususnya pembelajaran yang berbasis online. Metode penelitian ini menggunakan pendekatan deskriptif kualitatif dengan sample tiga sekolah dimana setiap sekolah diambil tiga kelas yang mempunyai kemampuan rata-rata yang berbeda. Hasil penelitian menunjukan bahwa terdapat 1 kelas di SMA N Balung yang mengalami kendala dalam menyelesaikan masalah matematika, 3 kelas dari SMA N Ambulu dan MAN 3 Banyuwangi tidak mengalami kendala dalam menyelesaikan masalah matematika. Berdasarkan hasil penelitian tersebut dapat disimpulkan bahwa penggunaan media Quiziz efektif untuk membantu mengatasi masalah matematika di masa pembelajaran berbasis online dan mempermudah guru dalam proses evaluasi.
\end{abstract}

Kata Kunci: Pembelajaran Online, Media Quiz

\begin{abstract}
The purpose of this study is to determine the effectiveness of Quiziz media in learning mathematics, especially online-based learning. This research method uses a qualitative descriptive approach with a sample of three schools where three classes are taken from each school with different average abilities. The results showed that there was 1 class at SMA N Balung who had problems solving math problems, 3 classes from SMA N Ambulu and MAN 3 Banyuwangi had no problems solving math problems. Based on the results of these studies, it can be concluded that the use of Quiziz media is effective to help overcome math problems in online-based learning and facilitate teachers in the evaluation process.
\end{abstract}

Keywords: Online-based Learning, Quiziz Media

\section{PENDAHULUAN}

Pandemi Covid-19 telah menimbulkan dampak yang sangat luar biasa terutama dalam bidang Pendidikan. Adanya Covid-19 mengakibatkan pembelajaran di Indonesia mengalami peralihan yaitu dari pembelajaran tatap muka menjadi pembelajaran online, dimana anatara guru dan siswa harus bisa beradaptasi dengan perubahan tersebut. Dapat kita lihat bahwasanya Ilmu pengetahuan berkembang mengikuti perkembangan zamannya. Sebagai seorang pendidik harus bisa memiliki strategi pembelajaran yang tepat bagi peserta didiknya agar tercipta pembelajaran yang Efektif.

Pembelajaran efektif menurut Supardi (2013) dapat didefinisikan sebagai suatu kombinasi yang tersusun meliputi manusiawi, material, fasilitas, perlengkapan dan prosedur diarahkan untuk mengubah perilaku siswa ke arah yang positif dan lebih baik sesuai dengan potensi dan perbedaan yang dimiliki siswa untuk mencapai tujuan pembe-lajaran yang telah ditetapkan. 
Hamalik (2001) menyatakan bahwa pembelajaran yang efektif adalah pembelajaran yang menyediakan kesempatan belajar sendiri atau memberikan kebebasan kepada siswa untuk belajar. Penyediaan kesempatan belajar sendiri dan memberikan kebebasan pada siswa diharapkan dapat membantu siswa dalam memahami konsep yang sedang di pelajari.

Miarso (2004) mengatakan bahwa efektivitas pembelajaran merupakan salah satu standart mutu pendidikan dan sering kali diukur dengan tercapainya tujuan, atau dapat juga diartikan sebagai ketepatan dalam mengelola suatu situasi, "doing the right things"

Efektivitas pembelajaran adalah tolak ukur keberhasilan dari suatu proses interaksi antar peserta didik maupun antara guru dengan peserta didik dalam situasi edukatif untuk mencapai tujuan pembelajaran. Keberhasilan tujuan pembelajaran dapat kita lihat dari aktivitas siswa selama pembelajaran berlangsung, respon siswa terhadap pembelajaran dan penguasaan konsep siswa. Untuk mencapai suatu konsep pembelajaran yang efektif dan efisien perlu adanya hubungan timbal balik antara siswa dan guru untuk mencapai suatu tujuan secara bersama, selain itu juga pembelajaran yang efektif harus dapat membentuk pola berpikir siswa terutama dalam pembelajaran matematika.

Pembelajaran matematika pada masa pandemi ini termasuk pada era revolusi 4.0 yang memiliki visi dan misi untuk membentuk pola berpikir seseorang menjadi mampu berpikir kritis, kreatif, komunikatif, dan kolaboratif."Mathematics is the bedrock of any contemporary order of science" (Thalhahet al., 2019).

Berpikir kreatif merupakan keterbukaan dalam berpikir dan responsive. Aktivitas berpikir kreatif anatara lain: merancang, menyampaikan gagasan, memecahkan masalah, dan mengkreasi. Proses siswa dalam mengembangkan kemampuan berpikir kreatif merancang suatu ide untuk pemecahan masalah, menggunakan pengetahuan dari informasi untuk mengkreasi untuk menemukan solusi dengan cara baru.

Cara mengadaptasi siswa untuk berpikir kreatif dalam pembelajaran jarak jauh yaitu disesuaikan dengan kondisi sarana dan prasarana sekolah, guru, serta kondisi peserta didik dan sarana/ prasarana pendukungnya. Meskipun berlangsung belum efektif, lembaga-lembaga penyelenggara pendidikan mencoba memaksimalkan alternatif yang dipilih sembari terus mengembangkan-nya sebagai upaya mendorong pembelajaran efektif dengan sejumlah keterbatasan-keterbatasan yang ada.

Keterbatasan dalam pembelajaran tidak menjadi halangan dalam menciptakan sebuah pembelajaran yang efektif. Salah satu upaya dalam mengefektifkan pembelajaran yaitu 
dengan menciptakan sebuah media pembelajaran yang menarik dan bersifat interaktif yang mengutamakan kerjasama, komunikasi, dan yang terpenting yaitu dapat menimbulkan interaksi antar siswa salah satunya yaitu melalui games. Dengan melalui games yang mempunyai karakteristik menciptakan motivasi dalam belajar, yaitu khayalan (fantasy), tantangan (challenges) dan keingintahuan (curiosity) (Irwan, dkk., 2019). Games atau permainan merupakan segala kontes yang menimbulkan interaksi satu dengan yang lain antara pemain dengan cara mengikuti atuan-aturan yang ada yang telah ditentukan dalam mencapai sebuah tujuan (Sadiman, dkk., 2010).

Pencapaian tujuan pembelajaran matematika berbasis games dapat dimanfaatkan sebagai evaluasi untuk mengukur pemahaman siswa selama siswa mendapatkan materi yang sudah diajarkan melalui media pembelajaran berbasis game edukasi Quizizz. Kegiatan pembelajaran di kelas dapat menjadi kegiatan yang membosankan bagi siswa jika evaluasi pembelajaran dilakukan secara monoton yaitu dengan teks dan juga dibacakan oleh guru, guru dapat menggunakan media evaluasi dengan memanfaatkan media pembelajaran yang bervariatif untuk menarik minat siswa. Penelitian ini didukung oleh penelitian yang telah dilakukan oleh Purba (2019) bahwa penggunaan media evaluasi pembelajaran Quizizz dapat meningkatkan konsentrasi belajar siswa. Penelitian yang dilakukan oleh Wihartanti, dkk., (2019) juga menyatakan bahwa terdapat perbedaan yang signifikan antara kelas yang menggunakan aplikasi Quizizz berbasis smartphone dibandingkan kelas yang menggunakan model konvensional dalam proses pembelajarannya. Pembelajaran dengan menggunakan aplikasi Quizizz juga mampu menumbuhkan kemampuan berpikir kritis.

Berdasarkan latar belakang dan penelitian terlebih dahulu peneliti akan melaksanakan penelitian yang berjudul: “ Efektifitas Media Quiz Di Masa Pandemi Covid-19” peneliti menggunakan judul ini karena ingin mengetahui efektivitas penggunaan media Quizizz terhadap hasil belajar siswa.

\section{METODE PENELITIAN}

Pada penelitian ini metode penulisan bersifat deskriptif berupa kata-kata tertulis dari informan dan perilaku yang diamati. Informasi didapatkan dari berbagai sumber melalui observasi dan dokumentasi jurnal untuk melengkapi data yang sesuai dengan permasalahan mengenai kendala dan akibat sebenarnya dari pandemi Covid-19 pada pembelajaran matematika dalam penelitian ini. 
Data yang terkumpul kemudian akan dianalisa menggunakan metode analisis data kualitatif. Menurut H.B Sutopo (2002) dalam Khabib Alia Akhmad analisis dimulai dari (1) reduksi data untuk mempertegas dan memfokuskan data sedemikian rupa sehingga simpulan penelitian dapat dilakukan, (2) sajian data dalam bentuk narasi yang disusun sistematis untuk menggambarkan fenomena yang menjadi kajian penelitian, (3) pengambilan keputusan yang telah memiliki landasan kuat setelah melalui proses analisa data.

\section{HASIL DAN PEMBAHASAN}

Hasil penelitian pertama didapatkan dari dokumentasi beberapa jurnal yang direduksi untuk memfokuskan data, didapatkan pernyataan sebagai berikut:

1. Penelitian yang dilakukan Briliannur Dwi Cahyani yang berjudul "Analisis Keefektifan Pembelajaran Online di Masa Pandemi Covid-19” mengatakan pembelajaran online yang dilakukan selama masa pandemi ini kurang efektif akibat kurangnya sarana dan prasarana yang didasari oleh faktor ekonomi beberapa sekolah didaerah tertinggal, serta faktor ketidaksiapan terhadap penguasaan teknologi yang dimiliki tenaga pendidik menghambat dalam berlangsungnya kegiatan belajar online.

2. Penelitian yang dilakukan Betty Kusumaningrum yang berjudul "Apakah Pembelajaran Matematika Secara Daring Efektif?" menyimpulkan bahwa meskipun sekolah memiliki sarana prasarana mencukupi untuk menunjang pembelajaran online, ternyaata masih mengalami kendala seperti ketidakstabilan akses internet. Pembelajaran matematika akan dikatakan efektif jika tersedia video pembelajaran, atau aplikasi pembelajaran yang kreatif sehingga meningkatkan motivasi dalam pembelajaran daring.

3. Penelitian yang dilakukan Sri Mulyati dengan judulnya "Pembelajaran matematika melalui media game quizizz untuk meningkatkan hasil belajar matematika smp 2 Bojonegoro" menyimpulkan penggunaan media quizizz yang mudah dan hasil yang cepat dalam proses penilaian menjadikan aplikasi ini layak digunakan sebagai aplikasi pembelajaran yang dapat mengatasi permasalahan selama proses pembelajaran matematika

Data kedua didapatkan dari hasil observasi yang hasilnya mencakup aspek (1) keefektifan dalam proses pembelajaran menggunakan media Quizizz, (2) pembelajaran tidak membosankan setelah penerapan media Quizizz, (3) meningkatkan motivasi pembelajaran 
setelah penerapan media Quizizz, dan (4) kebermanfaatan media Quizizz dalam pembelajaran online secara keseluruhan memenuhi kriteria baik.

Data untuk menunjukkan aspek keefektifan didukung oleh observasi yang dilakukan di SMA dari 3 daerah dengan tingkat kemampuan rata-rata yang berbeda. Pemilihan kelas yang beragam ini ditujukan agar data yang didapat mampu mewakili permasalahan yang dihadapi peserta didik dari berbagai tingkatan kemampuan. Hasil observasi tertuang sebagai berikut.

\begin{tabular}{|c|c|c|c|c|}
\hline \multirow[b]{2}{*}{ No. } & \multirow[b]{2}{*}{ Nama Sekolah } & \multirow[b]{2}{*}{ Kelas } & \multicolumn{2}{|c|}{ Hasil Observasi } \\
\hline & & & $\begin{array}{c}\text { Uji sebelum } \\
\text { menggunakan Quizizz }\end{array}$ & $\begin{array}{c}\text { Uji dengan } \\
\text { menggunakan Quizizz }\end{array}$ \\
\hline \multirow[t]{3}{*}{1.} & Sekolah Pertama & Responden ke-1 & 82.9285 & 89.5 \\
\hline & & Responden ke-2 & 83.7142 & 88.6428 \\
\hline & & Responden ke-3 & 88.5143 & 89.3571 \\
\hline \multirow[t]{3}{*}{2.} & Sekolah Kedua & Responden ke-4 & 83.5714 & 83.2142 \\
\hline & & Responden ke-5 & 83 & 82.1428 \\
\hline & & Responden ke-6 & 83.6428 & 89.3571 \\
\hline \multirow[t]{3}{*}{3.} & Sekolah Ketiga & Responden ke-7 & 82.2142 & 89.0714 \\
\hline & & Responden ke-8 & 83.0714 & 88.5 \\
\hline & & Responden ke-9 & 84.5714 & 88.9285 \\
\hline \multicolumn{3}{|c|}{ Rata-rata } & 83.9142 & 87.6348 \\
\hline
\end{tabular}

Hasil observasi menunjukkan antara nilai ujian menggunakan soal dalam bentuk file yang dibandingkan dengan nilai ujian ketika menggunakan media game Quizizz mengalami peningkatan. Di sekolah pertama dan ketiga mengalami peningkatan nilai rata-rata di ketiga kelasnya, sedangkan sekolah kedua hanya mengalami peningkatan di 1 kelasnya, sedangkan kedua kelasnya mengalami penurunan nilai rata-rata. Akan tetapi nilai siswa dari ke enam kelas yang diobservasi mendapatkan nilai diatas 80. Data ini memperkuat bahwa pembelajaran menggunakan game Quizizz yang dilakukan dalam penelitian ini efektif.

Aspek berikutnya yang harus dipenuhi untuk mencapai kriteria yang baik didukung dari data hasil wawancara yang dilakukan setelah pemberian ujian menggunakan Quizizz, yang sekaligus data ini untuk menjawab mengenai kendala yang dialami peserta didik, karena dari data kedua didapatkan 2 kelas yang mengalami penurunan nilai rata-rata setelah menggunakan Quizizz. Hasil dari wawancara tertuang dalam tabel berikut ini. 


\begin{tabular}{|c|c|c|c|c|}
\hline No. & Respon & Setuju & $\begin{array}{l}\text { Kurang } \\
\text { Setuju }\end{array}$ & $\begin{array}{l}\text { Tidak } \\
\text { Setuju }\end{array}$ \\
\hline 1. & $\begin{array}{l}\text { Pembelajaran menggunakan media game Quizizz } \\
\text { membantu memahami soal yang berkaitan dengan materi }\end{array}$ & $\sqrt{ }$ & & \\
\hline 2. & Lebih termotivasi mengerjakan soal menggunakan Quizizz & $\sqrt{ }$ & & \\
\hline 3. & Quizizz membantu saya untuk berpikir kritis & & $\sqrt{ }$ & \\
\hline 4. & $\begin{array}{l}\text { Saya merasa antusias setiap kali akan diberikan soal } \\
\text { menggunakan Quizizz. }\end{array}$ & & $\sqrt{ }$ & \\
\hline 5. & $\begin{array}{l}\text { Menggunakan Quizizz lebih fleksibel karena bisa saya } \\
\text { akses dimanapun }\end{array}$ & $\sqrt{ }$ & & \\
\hline 5. & Saya kurang menguasai cara penggunaan Quizizz & & $\sqrt{ }$ & \\
\hline 6. & $\begin{array}{l}\text { Sinyal yang tidak stabil menjadi penghambat utama setiap } \\
\text { kali saya mengerjakan soal }\end{array}$ & $\sqrt{ }$ & & \\
\hline 7. & $\begin{array}{l}\text { Saya terkadang tidak memiliki kuota internet yang cukup } \\
\text { untuk mengikuti pembelajaran daring }\end{array}$ & $\sqrt{ }$ & & \\
\hline 8. & $\begin{array}{l}\text { Saya merasa terganggu jika ada notifikasi lain seperti } \\
\text { notifikasi dari whatsApp ketika mengakses Quizizz }\end{array}$ & & $\sqrt{ }$ & \\
\hline 9. & $\begin{array}{l}\text { Saya tidak menyukai sistem mengerjakan soal dengan } \\
\text { menggunakan Quizizz. }\end{array}$ & & & $\sqrt{ }$ \\
\hline
\end{tabular}

Data hasil wawancara diatas menunjukan bahwa dari aspek pembelajaran tidak membosankan, meningkatkan motivasi dan aspek kebermanfaatan media Quizizz dalam pembelajaran online disetujui oleh sebagian siswa. Adapun manfaatnya ialah dapat membantu siswa untuk aktif memaksimalkan kemampuannya dalam memahami soal, menggugah sikap kompetitif siswa, menggugah siswa untuk bereksplorasi mencoba beberapa soal yang lain, serta membuat proses evaluasi lebih ditunggu-tunggu siswa karena ingin mencoba berkompetitif dengan peserta lain. Dari kelebihan yang dimiliki apabila proses evaluasi pembelajaran menggunakan media Quizizz diharapkan dapat mendorong siswa untuk lebih giat belajar untuk mendapatkan poin sebanyak mungkin, serta membantu menambah fokus dan ketertarikan mereka untuk mencoba berbagai soal melalui media game Quizizz.

Karena keempat aspek telah terpenuhi dengan baik dan didukung oleh data hasil observasi dan wawancara, maka penggunaan media Quizizz dalam dikatakan memenuhi 
kriteria yang baik. Meskipun masih terdapat kendala yang dirasakan sebagian siswa dan menjadi tantangan yang sulit diatasi, padahal penggunaan smartphone dalam pembelajaran adalah salah satu cara yang tepat dalam mengakses internet untuk membantu siswa mengikuti pembelajaran daring.

\section{SIMPULAN DAN SARAN}

Penggunaan smartphone dan laptop dalam pembelajaran daring dapat meningkatkan hasil belajar peserta didik. Quizizz memberikan data dan statistik hasil kinerja siswa secara langsung. Quizizz tidak hanya dapat dikerjakan siswa secara langsung, tetapi juga dapat digunakan sebagai soal latihan pekerjaan rumah (PR) yang dapat diakses kapan saja dan dimana saja asalkan tidak melebihi batas waktu yang sudah ditentukan

Kekurangan dalam penelitian ini ialah fokus pembahasan terhadap media pendukung yang dapat dilakukan oleh guuru selama masa pandemi, sehingga perlu adanya penelitian lebih lanjut mengenai permasalahan-permasalahan yang dialami oleh siswa selama masa pandemi dan cara pengefektifkan pembelajaran online dari sudut pandang siswa.

\section{DAFTAR PUSTAKA}

Agus P, R. P. (2020). Studi Eksploratif Dampak Pandemi COVID-19 Terhadap Proses Pembelajaran Online Di Sekolah Dasar. EduPsyCouns Journal, 2, 1-11.

Akhmad, K. A. (September de 2015). Pemanfaatan Media Sosial bagi Pengembangan Pemasaran UMKM (Studi Deskriptif Kualitatif pada Distro di Kota Surakarta). 9, 43-52.

Ali Sadikin, A. H. (2020). Pembelajaran Daring di Tengah Wabah Covid-19. BIODIK: Jurnal Ilmiah Pendidikan Biologi, 6, 214-224.

Aprida P, M. D. (2017). Belajar Dan Pembelajaran. FITRAH: Jurnal Kajian Ilmu-Ilmu Keislaman, 03, $333-351$.

Betty K, Z. W. (2020). Apakah Pembelajaran Matematika Secara Daring Efektif? (Studi Kasus pada Pembelajaran Selama Masa Pandemi Covid-19). KREANO: Jurnal Matematika Kreatif-Inovatif, 11, 137-141.

Briliannur Dwi, A. A. (s.d.). Analisis Keefektifan Pembelajaran Online di Masa Pandemi Covid-19. MAHAGURU: Jurnal Pendidikan Guru Sekolah Dasar, 28-37.

Cahyani Amildah, B. R. (2020). Keefektifan Penggunaan Media Pembelajaran Berbasis Game Edukasi Quizziz Terhadap Hasil Belajar Teknologi Perkantoran Siswa Kelas X SMK Ketintang Surabaya. Jurnal Pendidikan Administrasi Perkantoran (JPAP), 8, 261-271.

Dermawan, A. (2014). Keefektifan Collaborative Learning Berbasis Quiz Edutainment Terhadap Ketuntasan Hasil Belajar. Chemistry In Education, 3, 57-62.

Dwi, M. (2020). Pemanfaatan Teknologi Pendidikan Di Masa Pandemi Covid-19: Penggunaan Fitur Gamifikasi Daring Di Universitas Muhammadiyah Pringsewu Lampung. 1, 1-13.

Fakhrurrazi. (2018). Hakikat Pembelajaran Yang Efektif. Jurnal At-Tafkir, XI, 85-97.

Mohammad Mukhlis, D. H. (2018). Student Critical Thinking in Solving Two Dimensional Armetics Problems Based on 21th Century Skills. International Journal of Advanced Engineering Research and Science (IJAERS), 5(4), 19-30.

Mohammad Mukhlis, M. T. (2019). Instrumen Pengukur Creativity And Inovation kills Siswa Sekolah Menengah di Era Revolusi Industri 4.0. Indonesian Journal Of Mathematics and Natural Science Education, 1(1), 65-73. 
Nisa, M. M. (2020). Analisis Hubungan Antara Kecerdasan Logis Matematis Dengan Kemampuan Komunikasi Matematis Siswa. Alifmatika: Jurnal Pendidikan Dan Pembelajaran Matematika, 2(2), 199-211.

Saeful, P. (2009). Penelitian Kualitatif. EQUILIBRUM, 5, 1-8.

Sri M, H. E. (2020). Pembelajaran Matematika Melalui Media Game Quizziz Untuk Meningkatkan Hasil Belajar Matematika SMP 2 Bojonegara. GAUSS: Jurnal Pendidikan Matematika, 03, 64-72.

Tiya R, A. B. (2017). Perbandingan Hasil Belajar Siswa Menggunakan Media Daily ChemQuiz Dan Permainan Ranking One Chemistry Quiz. ALOTROP: Jurnal Pendidikan dan Ilmu Kimia, 1, 93-97.

Zailani Surya M, S. W. (2021). Upaya Mendorong Pembelajaran Efektif Masa Pandemi Melalui Pelatihan Inovasi Belajar Berbasis Digital. Jurdimas (Jurnal Pengabdian Kepada Masyarakat, 4, 165-172. 